\begin{tabular}{|c|c|c|}
\hline 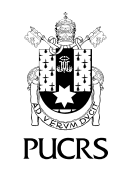 & $\begin{array}{l}\text { ESCOLA DE } \\
\text { HUMANIDADES }\end{array}$ & $\begin{array}{l}\text { Revista Digital do Programa de Pós-Graduação em Letras da PUCRS } \\
\text { Letrônica, Porto Alegre, v. 13, n. 1, p. 1-11, jan.-mar. } 2020 \\
\text { e-ISSN: } 1984-4301\end{array}$ \\
\hline de) $\mathrm{http}: / / \mathrm{dx}$ & $\mathrm{rg} / \mathbf{1 0} .15448 / 1984-4301.2020 .1 .36075$ & \\
\hline
\end{tabular}

\title{
La escritura de Clorinda Matto y Laura Riesco: Un siglo de literatura femenina
}

\author{
The writing of Clorinda Matto and Laura Riesco: A century of female literatura \\ Os escritos de Clorinda Matto e Laura Riesco: Um século de literatura feminina
}

\section{Sara Beatriz Guardia ${ }^{1}$ orcid.org/0000-0003-0364-3397 sarabeatriz.quardia@gmail.com}

Recebido em: 21 out. 2019 Aceito em: 21 out. 2019 Publicado em: 7 abr. 2020.
Resumen: La escritura femenina se inició en el Perú durante el periodo colonial entre los siglos XVII y XVIII, circunscrita a los conventos y conformada por cartas, documentos juridicos, testimonios, poesia, y una escritura autobiográfica propiciada por los confesores. A finales del siglo XIX surgió un importante movimiento de mujeres que incursionaron en la literatura; seguidas después por la vanguardia literaria y artística de la década del veinte; y de las contemporáneas. Voces que han emergido de una larga lucha que tuvieron que librar las mujeres para imponerse en una sociedad que les negaba el derecho de incursionar en aquello que siempre había sido reservado a los hombres: la literatura. En el presente artículo estudiamos dos novelas escritas con un siglo de diferencia: Aves sin nido de Clorinda Matto de Turner, publicada en 1889, y Ximena de dos caminos, de Laura Riesco, en 1994

Palabras claves: literatura. Mujeres. Novelas - siglo XIX-XX.

Abstract: The feminine writing began in Peru during the colonial period between the seventeenth and eighteenth centuries, circumscribed to convents and made of letters, legal documents, testimonies, poetry, and an autobiographical writing propitiated by the confessors. At the end of the 19th century an important movement of women who dabbled in literature emerged; followed by the literary and artistic avant-garde of the twenties; and of the contemporary. Voices that have emerged from a long struggle that women had to fight to prevail in a society that denied them the right to venture into what had always been reserved for men: literature. In this article we study two novels written with a century of difference: Aves sin nido by Clorinda Matto de Turner, published in 1889, and Ximena de dos caminos, by Laura Riesco, in 1994.

Keywords: literature. Women. Novels - 19th century - 20th century.

Resumo: A escrita feminina começou no Peru durante o período colonial entre os séculos XVII e XVIII, circunscrita a conventos e composta de cartas, documentos legais, testemunhos, poesia e uma escrita autobiográfica propiciada pelos confessores. No final do século XIX, surgiu um importante movimento de mulheres que se interessavam por literatura; seguido pela vanguarda literária e artística dos anos vinte; e do contemporâneo. Vozes que surgiram de uma longa luta que as mulheres tiveram que lutar para se impor em uma sociedade que lhes negava o direito de se aventurar no que sempre fora reservado aos homens: a literatura. Neste artigo, estudamos dois romances escritos com um século de diferença: Aves sem ninho, de Clorinda Matto de Turner, publicada em 1889, e Ximena de dos camino, de Laura Riesco, em 1994.

Palavras-chave: literatura. Mulheres. Romances - séculos XIX e XX. 
Las mujeres que escribieron en el Perú a finales del siglo XIX, constituyen la vanguardia literaria y artística que abrió el camino de su presencia en la literatura. Son voces que emergen del silencio, interpelan los discursos hegemónicos, exigen, critican y reinterpretan la tradicional cultura peruana a través de gestos que mezclan, desordenan diferentes niveles de sus construcciones, y dibujan nuevos mapas discursivos (MATTALIA, 2003, p. 26). Para de esta manera, articular las experiencias en la reconstrucción de la memoria y la ficción, lo que también significa un lenguaje propio, un espacio de liberación, de reconocimiento de sí mismas y de redefinición. Escritura que al romper el silencio, la marginalidad y la represión se convierte en una praxis simultánea de ruptura y transformación (CIXOUS, 1995), mediante las diferentes formas de representación que asume la pluralidad de las voces literarias femeninas.

Cobra particular importancia en este contexto la equivalencia histórica que existe entre dos novelas escritas con un siglo de diferencia: Aves sin nido de Clorinda Matto de Turner, publicada en 1889, y Ximena de dos caminos, de Laura Riesco, en 1994. Ambas muestran las contradicciones del mundo andino, y describen la marginación y opresión étnica-social y de género. Las categorias de sometimiento, injusticia y dominio alcanzan niveles similares en estas dos obras, aunque la novela de Riesco introduce la búsqueda de identidad y la formación de una conciencia femenina.

Elúltimo tercio del siglo XIX en el Perú, constituye un intenso periodo signado por la conciencia crítica de ideólogos y políticos respecto de la realidad social e histórica del país. Denunciaron el paternalismo y la intolerancia, y plantearon las bases de la modernización de la sociedad tradicional peruana en el contexto del desastre de la Guerra del Pacífico (1879-1883). Es en este espacio que se empiezan a conformar y precisar los discursos de identidad nacional, y se trazan los hitos de nuestra historia literaria y cultural.

Surgieron importantes revistas como "La
Revista de Lima" (1859 -1863/1873), "El Correo del Perú" (1871-1878) y "El Perú Ilustrado" (18871892), donde el aspecto cultural fue el factor predominante, así como la fuerte presencia y el magisterio de Manuel González Prada. En esta coyuntura surgió Clorinda Matto de Turner, autora de Aves sin nido, precursora de la novela indigenista en el Perú ${ }^{2}$, quien como señala Tauro (1976, p. 5) asumió una posición avanzada en el proceso de transformación del país al abandonar el ámbito doméstico para ejercer funciones directivas en el periodismo, y denunciar a los grupos de poder tradicionales, en especial la Iglesia. Por ello, su obra tiene un doble valor: literario y testimonial.

Elindigenismo, llamado en el siglo XIX indianismo, o indigenismo romántico, se propuso incorporar elementos de la tradición andina en el arte y la cultura, describir las costumbres y aspiraciones de los indigenas, y denunciar los abusos y atropellos que sufrian. La narrativa indigenista, como señala Cornejo Polar (1992), es un movimiento interdisciplinario que tiene sus raices en el trauma de la conquista, y que mantuvo vigencia hasta la década del veinte, cuando se le conoció como indigenismo, o indigenismo ortodoxo, signado por una intelectualidad regional emergente que buscaba las bases de la identidad peruana.

La revista cusqueña Kosko publicó el 30 de julio de 1925, el manifiesto: "De los Andes irradiará otra vez la cultura", reproducido después por la revista arequipeña, La Esfera, con el título de "El Andinismo" (LOPEZ 1998, p. 189). Manifiesto que con algunas variantes publicó Luis E. Valcárcel, en su libro La Tempestad en los Andes, donde afirma la resurrección de la raza quechua y el surgimiento de un "indio nuevo". Producto de una emoción similar al discurso de Manuel González Prada (1848-1918) pronunciado en el Teatro Politeama de Lima el 29 julio de 1886 cuando sostuvo que: "No forman el verdadero Perú las agrupaciones de criollos y extranjeros que habitan la faja de tierra situada entre el Pacífico y los Andes; la nación está formada por

2 La novela de Matto de Turner tiene antecedentes en El Padre Horán, de Narciso Aréstegui (1848); Coralay de Clemente Althaus (1853); y La Trinidad del indio o costumbres del interior, de José Torres Lara (1885). 
las muchedumbres de indios diseminados en la banda oriental de la cordillera"3.

Al referirse al libro de Luis Valcárcel, Tempestad en los Andes, José Carlos Mariátegui señaló que tenía algo de evangelio y hasta de Apocalipsis. Es la obra de un creyente, concluyó 4 . Para el autor de los Siete ensayos de interpretación de la realidad peruana (1928), estas afirmaciones no contenían los principios que restituirán a la raza indígena de su sitio en la historia nacional. Por ello, la cuestión nacional para Mariátegui incluía la problemática indigena, y en su capítulo "Proceso a la literatura" enfatiza que el "dualismo quechua-español del Perú, no resuelto aún, hace de la literatura nacional un caso de excepción que no es posible estudiar con el método válido para las literaturas orgánicamente nacionales, nacidas y crecidas sin la intervención de una conquista. Nuestro caso es diverso del de aquellos pueblos de América, donde la misma dualidad no existe, o existe en términos inocuos" (MARIATEGUI, 1992, p. 236). El desarrollo de la literatura peruana es pues el resultado de la tensión y contradicciones producidas por la conquista, ese encuentro violento entre dos mundos que dejó vencedores y vencidos confrontados dolorosamente en una sociedad dividida, plena de conflictos, acuerdos y discrepancias.

\section{Clorinda Matto de Turner y su tiempo}

Clorinda Matto nació en el Cusco el 11 de noviembre de 1852. Su infancia transcurrió en la hacienda familiar, Paullo Chico, donde aprendió a hablar el quechua, y supo del sufrimiento de los indigenas, hecho que tuvo una notable influencia en su vida. Estudió en el Colegio Nacional de Educandas, una de las escuelas para niñas más importante del Cusco, hasta que huérfana de madre a los diez años tuvo que abandonar los estudios para cuidar de su padre y sus hermanos. El 27 de julio de 1871, se casó con el médico ingles José Turnery se trasladó a vivir a Tinta, periodo en el que escribió obras de teatro, poesía y algunos artículos abogando por una educación para las mujeres, publicados con diferentes seudónimos (Rosario, Lucrecia, y Betsabé), en "El Heraldo", "El Mercurio", "El Ferrocarril" y "El Eco de los Andes".

Al estallar la Guerra con Chile en 1879, respaldó activamente al general Andrés Avelino Cáceres, convirtiendo su casa en hospital de guerra. En marzo de 1881, enviudó, y dos años después viajó a Arequipa, donde se desempeñó como jefa de redacción del diario "La Bolsa". Escribió su primer ensayo: "Literatura según el Reglamento de Instrucción Pública. Para uso del Bello Sexo"; y la serie de ensayos históricos: "Perú-Tradiciones cuzqueñas" (1884), con prólogo de Ricardo Palma, y en 1884, estrenó "Hima-Sumac", su única obra de teatro 5 .

El 3 de junio de 1886, ascendió a la presidencia de la República el general Andrés A. Cáceres, héroe de la resistencia y fundador del partido Constitucional. Ese año Clorinda Matto de Turner se trasladó a vivir a Lima, y durante su estadía entre 1886 y 1895 expresó de manera abierta su apoyo al general Cáceres. En Narraciones históricas dice: "Serviamos al Partido Constitucional, por la convicción de sus honrosas tradiciones, porqué él nació bajo la bandera de la defensa del Perú contra el invasor, porque de su seno salieron los que sin cobardias desertoras ni apostasias calculadas, fueron siempre con el lema de la Patria". Adhesión que le valdría el odio de Nicolás de Piérola, a quien calificó de traidor.

En Lima se incorporó a las reuniones literarias del Ateneo, y el Círculo Literario ${ }^{6}$, al que asistía Manuel González Prada, cuyas ideas sobre la cuestión nacional, educación de los indígenas y anticlericalismo influyeron notoriamente en la escritora. Dirigió "El Perú Ilustrado" durante tres años, la revista literaria más importante de Lima que desde su primer editorial en 1889, destacó la importancia de una literatura "peruanista"7. Precisamente en "El Perú Ilustrado" del 3 de

\footnotetext{
Publicado en Páginas Libres y citado por Alberto Tauro, 1976, p. 41.

Prólogo de José Carlos Mariátegui al libro de Luis E. Valcárcel, Tempestad en los Andes, 1927.

Hima-Sumac. Drama en tres actos. Lima: Imprenta La Equitativa, 1892.

En 1866 un grupo de bohemios creó el Centro literario que después se convirtió en la Sociedad Amigos de las Letras, y más tarde en 1873 en Club Literario. Juana Manuela Gorriti fundó el Círculo Literario en 1876, un año después recibió a Clorinda Matto cuando llegó a Lima.

7 "El Perú Ilustrado" fue de periodicidad semanal y concentró la abundante producción literaria de entonces en la que participaron las escritoras: Juana Manuela Gorriti, Teresa González de Fanning, Carolina Freyre de Jaimes, Mercedes Cabello de Carbonera, Lastenia Larriva de Llona, Juana Rosa de Amézaga, Amalia Puga de Losada y Maria Nieves y Bustamante.
} 
mayo de 1890, apareció publicada la carta que le dirigiera el presidente Cáceres, a propósito de la publicación de su novela Aves sin nido. Allí le dice que ha descrito "con una exactitud digna de encomio lo que ocurre en la sierra y que yo, en mi larga peregrinación, he podido observar". Y señala que sería necesario "hacer una peregrinación de pueblo en pueblo, estancia por estancia, aldea por aldea, a fin de corregir esos abusos, teniendo una mirada investigadora y la firme convicción de hacer el bien". Carta que revela que el primer indigenismo pudo haber estado asociado al proyecto político de reconstrucción nacional liderado por el general Cáceres, figura emblemática de la resistencia del mundo andino durante la guerra.

Además de Aves sin nido (1889), Clorinda Matto de Turner escribió: Tradiciones cuzqueñas (1884); Tradiciones cuzqueñas. Tomo II. (1886); Bocetos al lápiz de americanos célebres (1889); Elementos de Literatura según el Reglamento de Instrucción Pública para uso del bello sexo (1889); Índole (1891); Hima-Sumac (1892); Leyendas y recortes (1893); Herencia (1895); Analogía. Traducción al quechua de los evangelios de San Juan, San Pablo, San Marcos y San Mateo; Boreales, miniaturas y porcelanas (1902); Cuatro conferencias sobre América del Sur (1909); Viaje de Recreo. España, Francia, Inglaterra, Italia, Suiza, Alemania (1909).

El 23 de agosto de 1890. Clorinda Matto fue denunciada por el Arzobispo de Lima por la publicación en "El Perú Ilustrado" del cuento Magdala de Henrique Maximiano Coelho en el que aparece un terrenal Jesús interesado en Maria Magdalena. El Arzobispo la excomulgo y le dio categoría de pecado la lectura o la propagación de la revista, prohibiéndola al clero y a la feligresía; y "llevando a su clímax esta campaña ultramontana, el obispo de Arequipa extendió la interdicción eclesiástica a la lectura de Aves sin nido y favoreció la realización de una poblana callejera, durante la cual fue arrojada al fuego la efigie de la combativa escritora" (TAURO, 1976, p. 17).

Matto renunció a la dirección de la revista el 11 julio 1891, y en 1892 fundó La Equitativa, imprenta donde empleó solamente a mujeres. Pero pronto se vio envuelta en la contienda que enfrentó al general Andrés Avelino Cáceres contra la coalición acaudillada por Nicolás de Piérola el 17 y 18 de marzo de 1895. Durante esos dias la casa de la escritora fue asaltada y la imprenta destruida. Poco después, el 25 de abril de 1895 partió en el vapor Maipo con destino a Valparaíso, para de alli llegar por tren a Santiago, Mendoza y Buenos Aires. Tras nueve años de exilio murió el 25 de octubre de $1909^{8}$.

\section{Aves sin nido}

Con Aves sin nido, publicada en 1889 nace la novela indigenista en el último tercio del siglo XIX, coincidiendo con una coyuntura significativa para el pais cuando se empezaba a bosquejar las bases de una incipiente modernización de la sociedad peruana. ${ }^{9}$ El tema central es la denuncia del maltrato y opresión que sufrian los indios, y la corrupción e incompetencia de jueces, gobernadores y clérigos. En la novela, Matto de Turner juega "con la autorización del letrado para asumir la voz en nombre del otro desvalido y saqueado por el poder" (MATTALIA 2003, p. 286); y revela, como señala en el prólogo Emilio Gutiérrez de Quintanilla, "el estado social vergonzoso y alarmante en que se halla este pueblo numeroso que en la región andina ocupa la mayor parte del territorio peruano" (VELARDE, 1943, p.18).

En el proemio de la novela Clorinda Matto expresa las intenciones y objetivos de su novela y la razón de su escritura.

"Si la historia es el espejo donde las generacio-
nes por venir han de contemplar la imagen de
las generaciones que fueron, la novela tiene
que ser la fotografia que estereotipe los vicios
y las virtudes de un pueblo, con la consiguiente
moraleja correctiva para aquéllos y el home-
naje de admiración para éstas" (MATTO, 1889).

La novela se presenta así como un espejo realista de la vida con la intención de conservar

\footnotetext{
8 En 1924 sus restos fueron trasladados al Perú y enterrada en Lima.

9 Clorinda Matto de Turner. Aves sin nido. Buenos Aires: Félix Lajouane, 1889. Ese año tuvo otra edición en Buenos Aires, después en España por la Editorial Sempere, y otra traducida al inglés por J. G. Hudson y Charles J Tiñe, en 1904.
} 
la memoria, pero sobre todo como reformadora de las injusticias y vicios de un pueblo, porque tiene la capacidad de "ejercer mayor influjo en la morigeración de las costumbres":

¿Quién sabe si después de doblar la última página de este libro se conocerá la importancia de observar atentamente el personal de las autoridades, así eclesiásticas como civiles, que vayan a regir los destinos de los que viven en las apartadas poblaciones del interior del Perú"? (MATTO, 1889).

Y para que su voz sea reconocida y creida, enfatiza que es la voz de quien ama y de quien como testigo del oprobio se erige en defensora:

"Amo con amor de ternura a la raza indígena, por lo mismo que he observado de cerca sus costumbres, encantadoras por su sencillez, y la abyección a que someten esa raza aquellos mandones de villorio, que, si varian de nombre, no degeneran siquiera del epiteto de tiranos. No otra cosa son, en lo general, los curas, gobernadores, caciques y alcaldes". (MATTO, 1889).

Una joven pareja, Fernando y Lucía Marín, Llega a un pueblo imaginario de la región andina llamado Killac por razones de trabajo de Fernando en la industria minera. Acostumbrada a la vida de la capital pronto la pareja se enfrenta a una realidad signada por el maltrato y explotación al que son sometidos los indios, agobiados por los impuestos que deben pagar porque de lo contrario corren el riesgo de perder sus humildes bienes y hasta sus propios hijos, y donde las mujeres obligadas a trabajar en las casas parroquiales terminan a veces vejadas sexualmente por algún clérigo.

En el primer capítulo, Marcela Yupanqui, descrita como "una mujer rozagante por su edad, y notable por su belleza peruana", de unos treinta años y vestida "con una "pollerita flotante de bayeta azul oscuro y un corpiño de pana café, adornado al cuello y bocamangas con franjas de plata falsa y botones de hueso", acude a casa de Lucia Marín en busca de apoyo:

"En nombre de la Virgen, señoracha, ampara el dia de hoy a toda una familia desgraciada", clama desesperada, y le cuenta que su marido Juan Yupanqui, no tiene dinero para pagar la multa de ocho reales por la falla, dinero que se le imponía al indio por cada dia que no prestaba servicio comunal de los cuarenta que anualmente le eran obligatorios. Las lágrimas y la angustia de Marcela sorprenden a Lucia "pues residiendo pocos meses en el pueblito ignoraba el drama que vivian los indigenas".

"Como tú no eres de aquí, niñay, no sabes los martirios que pasamos con el cobrador, el cacique y el tata cura, iay!, iay! ¿Por qué no nos llevó la Peste a todos nosotros, que ya dormiriamos en la tierra?" - Llora Marcela Yupanqui (MATTO, 1889, p. 8).

Indignada, Lucía asume la defensa de los Yupanqui, y agrega despidiendo a Marcela: "Anda ahora a cuidar de tus hijas, y cuando vuelva Juan tranquilizalo, cuéntale que has hablado conmigo, y dile que venga a verme". Ante la ausencia del esposo, Lucia ha tomado la decisión salir del espacio privado y doméstico de su casa y presentarse ante el gobernador,

\begin{abstract}
"iTriste realidad, señores! iY bien!, vengo a persuadirme de que el vil interés ha desecado también las más hermosas flores del sentimiento de humanidad en estas comarcas, donde crei hallar familias patriarcales con clamor de hermano a hermano. Nada hemos dicho; y la familia del indio Juan no solicitará nunca ni vuestros favores ni vuestro amparo. -Al decir estas últimas palabras con calor, los hermosos ojos de Lucía se fijaron, con la mirada del que da una orden, en la mampara de la puerta". (MATTO, 1889, p. 13).
\end{abstract}

La intervención de Lucia genera una fuerte reacción en las autoridades. Todos coinciden en que es necesario: "botar de aqui a todo forastero que venga sin deseos de apoyar nuestras costumbres; porque nosotros, francamente, somos hijos del pueblo..." (MATTO, 1889, 23). Pero para estas autoridades civiles y religiosas en el pueblo no están comprendidos los indios:

"...la señora Lucía nos ha llamado para abogar por unos indios taimados, tramposos, que no quieren pagar lo que deben, y para esto ha empleado palabras que, francamente, entendidas por los indios destruyen de hecho nuestras costumbres de reparto, mitas, pagos y demás." (MATTO, 1889, p. 30)

Los poderosos, al mando del párroco y el gobernador asaltan la casa de Fernando y Lucía Marín con la intención de asesinarlos, pero quienes mueren son los Yupanqui dejando dos hijas, Margarita y Rosalía, que son adoptadas por la 
pareja. Aqui termina la primera parte de la novela ${ }^{10}$.

Asi el intento de negociar más allá del espacio privado y doméstico, desencadena la violencia que causa la muerte de Marcela Yupanqui y de su marido. El enfrentamiento entre los buenos y malos, entre los poderosos y los indios, se focaliza en la figura de dos mujeres, la buena, dulce y culta Lucia Marin y la india buena, Marcela Yupanqui. Juntas emprenden acciones de resistencia y con su fuerza atraen a sus maridos, el ingeniero y el indio agricultor.

La segunda parte está centrada en la defensa de la familia de Isidro Chambi, en quien las autoridades locales descargan la responsabilidad del asalto a la casa de los Marín, y al que un abogadillo engaña robándole sus vacas con la promesa de liberarlo de la prisión. Este hecho hace que retrasen el retorno a Lima donde Margarita y Rosalia, podrán iniciar una nueva vida. Estudiarán, aprenderán música y tendrán la oportunidad de tener una vida reservada a las jóvenes de la elite.

Pero, Margarita se enamora de Manuel Pancorbo, joven profesional que estudia derecho en Lima e hijo del gobernador, con quien desea casarse. Cuando Manuel se presenta ante el padre adoptivo a pedir la mano de Margarita, le cuenta que en realidad no es hijo de don Sebastián Pancorbo sino del obispo Pedro Miranda. Declaración que desencadena el drama, puesto que Margarita es también hija del obispo. Entonces Fernando y Lucía abandonan "aquel pueblo donde campean el abuso y la avaricia, para trasladarse a la capital y buscar sosiego al amparo de las garantías que ofrecen la civilidad y la ley" (TAURO, 1976, p. 33).

Lucía y Marcela son los personajes protagónicos del relato. Son ellas las que se erigen en defensoras de la justicia transgrediendo el discurso patriarcal hegemónico de fines del siglo XIX donde las mujeres aparecen indefensas, como personas que requieren de apoyo y conducción para desenvolverse en la esfera pública. Son ellas las que constituyen las claves de la relación entre mujeres y hombres, entre indios y blancos; y son las que dan el primer paso al confiar y pedir ayuda a otras mujeres y a hombres que consideran sus aliados. Incluso es Lucia quien decide adoptar a Margarita y a Rosalia Yupanqui, contando con el apoyo de su esposo. Son las heroínas, como concibe George Lukács en la novela decimonónica basada en un héroe y su relación problemática con la sociedad. Porque es Lucia Marín quien ante las injusticias desafía a las autoridades locales del pueblo, y la que produce el cambio; y es Marcela Yupanqui la que contraviniendo las reglas establecidas busca apoyo en Lucia.

Las otras mujeres que aparecen en el relato cumplen funciones menores como Martina Chambi, decidida también a pasar a la acción para lograr la liberación de su marido preso, pero recurre a la persona equivocada, al compadre Escobedo que le ofrece su apoyo a cambio de cuatro vacas:

\section{-¿Con cuatro vacas saldrá libre mi Isidro? \\ -¿Como no comadritay? Una daremos al gober- nador, otra al juez, otra al subprefecto, y la última quedaría, pues, para tu compadre".}

Cuando Martina relata lo ocurrido a Isidro éste se percata que no tiene salvación pues Escobedo los ha estafado. Sin embargo, Martina insiste aunque finalmente su esposo es liberado por Lucia y Fernando Marin. Otra mujer, Petronila, esposa del gobernador y madre de Manuel, se salva de la violencia gracias a su naturaleza bondadosa que le permite mantener cercanía con los Marin pero sin intervenir. Sufre en silencio con la esperanza de ser redimida por su hijo, lo cual no sucederá puesto que el amor entre Margarita y Manuel, es un amor imposible, ambos son aves sin nido, son hermanos, hijos del párroco de Killac, que abusó sexualmente de Marcela y Petronila.

En un ensayo sobre el vínculo entre novela y modernidad, Cornejo Polar lee en Aves sin nido una alegoría donde la familia es la metonimia de la nación. Los Marín representan a los blancos buenos que cuando conocen la explotación de los indios se erigen en salvadores e incluso adoptan las hijas de los Yupanqui para que estudien en los mejores colegios de Lima.

En esta lectura subyace un "significado turbador:

10 La primera parte de la novela está compuesta por 26 capítulos, y la segunda por 32 capítulos. 
la salvación del indio depende de su conversión en otro, en criollo. Metáfora integradora, por consiguiente, la adopción de Margarita y Rosalía expresa el deseo de una nación homogénea, abarcadora de la disidencia indígena a través de la educación aculturadora de sus miembros, obviamente considerados como menores de edad." (CORNEJO POLAR, 1994, p. 133). Así la liberación del indio se plantea a través de la educación y la buena intención de los blancos.

¿QQuien libertará al indio? pregunta Clorinda Matto en la novela, y ella misma deja sin respuesta una interrogante sin resolución hasta la fecha: "Asi que usted ha libertado a Isidro Chambi; iOh! Y ¿quién libertará a toda su desheredada raza? iEsta pregunta habria que hacerla a todos los hombres del Perú, querido amigo!" (TAMAYO VARGAS, 1968, p. 701).

Otro aspecto que singulariza la novela de Matto de Turner, es "el punto de vista narrativo hacia el universo femenino que difumina al otro masculino y se focaliza sobre las otras mujeres (MATTALIA, 2003, p. 286), estableciéndose una alianza de género. La modernidad en términos de romper las reglas y los valores tradicionales a través del tratamiento a las mujeres, a los indios, al sistema político y social, posibilita como dice Cornejo Polar, que la obra de Matto puede ser leída como una reflexión sobre la modernización del país y la construcción de una nueva identidad basada en la integración de la mujer a la vida social y económica, y la integración de la comunidad indigena liberada de los abusos a los que es sometida.

\section{Ximena de dos caminos}

En los años cincuenta la narrativa peruana pasó del tratamiento de temas exclusivamente rurales a la exposición de la temática urbana (FORGUES, 1988, p. 11). Por entonces se había acentuado la intensa y continua migración del campo a Lima que se inició varios años antes, y que transformó la ciudad originando una nueva configuración de los espacios sociales y culturales. Surgió así una tercera etapa, llamada neoindigenismo, que se caracterizó por el uso del realismo mágico, técnicas narrativas innovadoras, y la intensificación del lirismo. Los escritores de esta generación introdujeron cambios en los temas y en su tratamiento de la ciudad, y de la vida marginal de sus pobladores. De esta manera, los cánones del indigenismo, como señala González Vigil, cedieron paso a una narrativa que privilegiaba la exploración del hombre de clase media.

En la década del ochenta confluyeron varios elementos que posibilitaron aún mayores cambios como la incorporación creciente de la mujer en el mercado del trabajo, y el surgimiento de organizaciones feministas y organizaciones populares de mujeres, que sacudieron la sociedad limeña de su letargo y de su discurso patriarcal, tradicional y conservador, (GUARDIA, 2013, p. 196). En tanto que la narrativa volvió otra vez su mirada a los andes, y la violencia se convirtió en tema central.

Hecho que se advierte en la década del noventa en obras de gran calidad literaria como con La violencia del tiempo (1991), La destrucción del reino (1992), y Babel, el paraiso (1993), de Miguel Gutiérrez; Los eunucos inmortales (1995), de Oswaldo Reynoso; Pais de Jauja (1990) y Libro del amor y de las profecias (1999) de Edgardo Rivera Martínez. Pero además de los consagrados Alfredo Bryce, Mario Vargas Llosa y Julio Ramón Ribeyro, que siguieron brillando con luz propia, lo significativo de estos años fue la presencia de una narrativa de jóvenes escritores, y el surgimiento de un conjunto de novelas escritas por mujeres: Las dos caras del deseo (1994), de Carmen Ollé; Ximena de dos caminos (1994), de Laura Riesco; La espera posible (1998), de Grecia Cáceres; y La mentira de un fauno (1998), de Patricia de Souza.

Aunque es probable que no se pueda hablar de tendencias en la llamada narrativa andina, hay una corriente que refleja la marginación y explotación de los indigenas en un contexto de crisis social signada por la violencia generada por el terrorismo de la década del 80; mientras que otra está centrada en la formación de la subjetividad de los protagonistas como, por ejemplo, Ximena de dos caminos de Laura Riesco, "una de las novelas más notables publicadas en los últimos años que constituye una muestra ejemplar de novelar la realidad andina, lejos de los viejos tópicos establecidos por el indigenismo" (GUTIÉRREZ,1996, p. 36). 
Publicada en 1994, Ximena de dos caminos, destaca por la capacidad literaria de su autora quien demuestra ser dueña de "un mundo creador claramente propio, hondo y complejo, capaz de dialogar (conservando su tono intransferible) con una masa textual copiosa y diversa" (GONZÁLEZ VIGIL, 1995). Esta compuesta de siete textos autónomos ${ }^{11}$ que siguen un proceso "hacia un desenlace que ilumina, retrospectivamente, lo narrado y le confiere el carácter de fin de una etapa y comienzo de otra en la vida de la protagonista" (RIVERA MARTÍNEZ, 1995). Se podría decir, sostiene la autora, que se trata de "una novela de textos" donde la ficción está en función de las experiencias y vivencias de una niña de siete años, hija única de un matrimonio que vive en La Oroya a comienzos de la década del 40, enclave minero por entonces explotado por la transnacional norteamericana Cerro de Pasco Cooper Corporation, situado a 170 kilómetros de Lima y a una altitud de más de tres mil metros sobre el nivel del mar.

Aquí Ximena vive la violencia expresada en los juegos, los sentimientos encontrados que le suscitan algunos hechos, y el silencio cómplice de las mujeres de su entorno. Su infancia transcurre entre el mundo de su padre de origen español y funcionario de la compañia norteamericana, y el de su madre que procede de la misma región andina, acompañada de criadas todas de origen indigena. Ximena tiene que enfrentarse a esta lucha donde pugna la lógica patriarcal y la tradición oral de las mujeres indígenas que la cuidan y pueblan sus dias de magia y melancolía, como la Ama Grande, que al igual que otras mujeres que figuran en el relato están solas, incomprendidas, frustradas en su amor, y enajenadas por su propia historia.

Ximena transita por este universo sorteando dificultades y retos en la exploración de su mundo interior, convirtiendo así la búsqueda de su propia identidad en el largo camino que deberá recorrer para lograr finalmente su liberación a través de la palabra. Liberación que se plantea en una sociedad dividida entre dos culturas, dos universos: el de los indios y el de los "blancos". Allí, no existe neutralidad posible, "hay, por el contrario, choque y oposición permanentes, contradicciones agudas, insalvables" (CORNEJO POLAR, 1971).

El relato está presentado desde la intimidad del espacio privado, doméstico, así la "ficción de Riesco puede calificarse como una novela de atmósfera y de aprendizaje, donde cada uno de los hechos narrados está al servicio de un objetivo mayor (...) El relato escoge una narración en tercera persona a lo largo de todo el texto, pero la visión del narrador no es la estrictamente omnisciente, aunque formalmente lo parezca. En esa aparente objetividad que algo podría tener que ver con la narrativa de Marguerite Duras, está presente el punto de vista de Ximena" (MARTOS, 1999, p. 305).

En esteámbito íntimo que es su casa la fascinación por la escritura se manifiesta desde el primer capítulo cuando Ximena encuentra en la enciclopedia de su padre "la figura solitaria de un abedul dibujado en blanco y negro, rodeado de las columnas severas que forman las palabras", semejante a la seducción que le producen los caracteres mágicos delalfabeto árabe que acaricia "pensando que hay quienes pueden leer y cantar en esos signos misteriosos" (RIESCO 1994, p. 11). Palabras que no todos los mayores leen igual, porque su madre cuando lee cuentos cambia de entonación al tratarse de princesas, o brujas; en cambio su papá, y el tío Jorge leen sin ninguna variación.

Entre las mujeres que rodean a Ximena, el Ama Grande, la vieja criada india, es sin duda la más significativa, una suerte de abuela presente en todo el relato que acoge a la niña con ternura, la única capaz de tranquilizarla, y de contarle cuentos andinos que vienen de muy lejos. Otras también influyen de manera significativa como Casilda, la "ahijada" de su madre que llega de Lima en busca de refugio, presuntuosa, desagradable, llena de desplantes hacia Ximena y sobre todo a los sirvientes andinos.

Pero Ximena sabe que debe ser amable con Casilda porque a través de algunas conversaciones se entera que ha huido del colegio de monjas por un

11 "Los juguetes", "La ahijada", "Los primos", "Alcinoe Il o las tejedoras", "La costa”, "La feria” y "La despedida”. 
probable embarazo de un hombre casado a quien escribe desesperadamente sin ninguna respuesta. La escritura de la prima se convierte asi en la paradoja de la espera, y al final en su negado interlocutor cuando al no recibir respuesta reemplaza las cartas que nunca llegan por las suyas hasta que sobreviene el suicidio y el fin de la escritura:

Ximena quiere escapar hacia el patio, pero en vez de darse la vuelta, involuntariamente da dos pasos adelante. Sus zapatos chocan con la pantorrilla de Casilda. A la mano izquierda, sobre una tablas viejas, Ximena ve sin comprender unas hojas sueltas, la pluma que usa para escribir la ahijada y sobre el frasquito de láudano, que reconoce de inmediato, una navaja de afeitar (RIESCO 1994, p. 53).

El descubrimiento del sexo que comporta el machismo y la marginalidad que sufre la mujer se produce cuando Ximena juega con Cintia y Edmundo. El niño se imagina alcalde, un hombre con poder y sus primas son sus mujeres, le pertenecen, y por consiguiente puede imponerles juegos violentos y esperar que los acaten con sumisión. Tienen que desnudarse para que él observe desde su puesto de amo y señor el sexo y el doliente pudor de las niñas. Poco después las inicia en una ceremonia secreta donde es sacrificado un pequeño pato:

"La punta del acero no está suficientemente afilada y penetra con dificultad. Un sonido leve, que es apenas un crujir, se oye en un silencio tan puro que ni las ramas de los eucaliptos lo suavizan para prohibir que se alcen en el aire. A Edmundo le tiemblan las manos del esfuerzo. Por unos segundos que se hacen larguísimos el animal se mueve aún, aletea ritmicamente y tiene la cabeza erguida. De un tirón su primo desprende el cuchillo manchado. Es sólo después de otros segundos igualmente penosos que la sangre empieza a correrle por la mano" (RIESCO, 1994, p. 73).

La exposición del sexo y el sacrificio del pequeño animal anticipan simbólicamente desde la infancia la sujeción que vivirán las mujeres durante toda su vida. $Y$, es en este mundo masculino, donde Ximena tiene sentimientos, "angustias e impulsos reprimidos que no siempre afloran a la superficie". (BAQUERIZO, 1997, p.1). Aquí escucha la voz de la abuela que habla a través de un cuaderno que la madre lee en voz alta creyéndola dormida. Sin preámbulos ni disculpas, la abuela recuerda su vida, marido e hijas, pero sobre todo a sus amantes. Es el único personaje lúdico de la obra, la única mujer que logra imponerse al medio y a su época.

El capítulo "Alcinoe II o las tejedoras", tiene como fondo la historia del amor desgraciado de Heathcliff y Catherine en Cumbres Borrascosas. Semejante al amor de la mujer que abandona a sus hijos en Trujillo para seguir a Robertson, un mecánico norteamericano de la compañía donde trabaja el padre de Ximena, que es expulsado del trabajo convirtiéndose en chofer mientras su mujer trabaja como tejedora. Pero el amor, pasa a segundo plano cuando la madre se pregunta: ¿Qué le ha visto Robertson a esta mujer mestiza?:

\begin{abstract}
La Tejedora es pequeña y muy morena. Lleva el cabello negro en una permanente corta y se pone color en los labios. No lleva faldellines ni lliclla como otras que vienen a la casa para vender la manteleria que bordan o que tejen. Se viste en tonos oscuros y usa zapatos toscos de tacón alto, quizá porque es tan baja. Su madre ha comentado alguna vez que es "una cosita de nada" y que no comprende cómo Samuel Robertson perdió la cabeza por ella (RIESCO, 1994, p. 94).
\end{abstract}

La crueldad ejercida contra las mujeres aparece en dos episodios que tienen lugar en el modesto hotel del pequeño pueblo costeño donde la familia de Ximena pasa el verano. Pronto ella descubre la presencia misteriosa de una niña casi de su misma edad que vive detrás del portón amarrada a un árbol porque no tiene quien cuide de ella, y que interminablemente repite el mismo movimiento. Humillada y vencida la niña no atina a nada, en postura semejante a la segunda esposa de Don Serafino, el dueño del hotel, quien engañado por su primera esposa vuelca su furor en ese cuerpo que no se protege ni se defiende hasta que la mata a golpes.

Al final de la novela, en el capítulo "La despedida", mientras los padres preparan la mudanza a Lima, aparece la clave del relato cuando al intentar escribir su primera palabra aparece ante Ximena una mujer que escribe recuerdos imaginados y que requiere de su voz para completarlos. Así la narradora se constituye en personaje y reta a Ximena que relate aquellos recuerdos que más le duelen, para 
arrancarse definitivamente la infancia y sus dolores a través de la escritura. Las dos escriben, una para completar la historia, y la niña para iniciarla. La escritura como "un recorrido incierto por las sendas tortuosas del temor y el auto-reconocimiento" (RIESCO, 1994), que puede conducir a la liberación.

¿Qué pasó en el campamento de los obreros?, es la primera pregunta que da curso al desarrollo de la narración. Son estas dos mujeres, Ximena niña y Ximena mujer las que muestran el drama de la explotación, la usurpación de las tierras comunales, el despojo. Al producirse un incendio en el campamento minero, Ximena no quiere recordar la casa donde se ha escondido del fuego, pero ante la pregunta y obligada a hablar dice: "No había camas, ni muebles nada más que pellejos sobre el piso, unos atados, dos ollas y algunos tazones de metal. Recordó como en un sueño que su madre y el Ama Grande habian comentado lo mal que vivían los obreros de la fundición" (RIESCO 1994, p. 220).

En este cuarto pequeño y desvencijado Ximena encuentra a Pablo, un niño de su edad. Durante una entrecortada conversación y a modo de respuesta ante el conflicto que ha originado la huelga de los obreros, Pablo le explica con la naturalidad del lenguaje infantil como la transnacional los ha despojado de sus tierras con la anuencia de las autoridades locales, pero que la presencia de los estudiantes universitarios ha permitido que los obreros comprendan que no tienen por qué soportar más abusos de la compañía que se ha apropiado de las tierras que siempre pertenecieron a las comunidades indígenas. Y así se inicia la huelga, que concluye con el incendio y el ingreso de patrullas de la policía.

Sobre el silencio del campamento minero destruido solo queda la esperanza. Algún día, el Inca, cuyo cuerpo ha sido descuartizado y enterrado en varios lugares del país, resucitará para liberar a su pueblo. El mito de Inkarrí está incorporado como uno de los recuerdos que Ximena debe aceptar y reconstruir para la escritura. Solo entonces, puede tomar el lápiz y contemplar el papel en blanco sabiendo que finalmente podrá escribir.
La escritura se presenta asi como una búsqueda de identidad en el proceso de formación subjetiva y de una conciencia femenina, que conduce a la liberación personal cuando después de llevar consigo los recuerdos de su infancia, tal como le dice la mujer antes de partir, pueda arrancarlos para seguir adelante en el camino de otros cuentos. Entonces Ximena toma el lápiz y contempla el papel blanco:

\begin{abstract}
"Se agacha y distancia de todo lo que la rodea, se agacha para volcarse en los signos que el dificil silabeo le dicta, borra, para empezar. $Y$ mientras Ximena se ausenta, las palabras, en su ir y venir de la vida a la muerte, de la muerte a la vida, van fijándose y llenando su primera página" (RIESCO, 1994, p. 236).
\end{abstract}

\section{Bibliografía}

ARANGO-KEETH, Fanny. Del "Ángel del hogar" a la "obrera del pensamiento": Construcción de la identidad socio-histórica y literaria de la escritora peruana del siglo diecinueve. In: ANDREO, Juan; GUARDIA, Sara Beatriz. Historia de las mujeres en América Latina. Murcia: Universidad de Murcia, CEMHAL, 2003 https://doi.org/10.31819/9783964567215-017

BAQUERIZO, Manuel. Laura Riesco y la configuración narrativa del mundo infantil. Huallallo: Revista del Departamento Académico de Lingüística, Literatura y Arte de la Universidad Nacional del Centro del Perú, Lima, año 1, abr./ jun. 1997. https://doi. org/10.17013/risti.26.1-16

BERG, Mary G. Clorinda Matto de Turner: Periodista y critica. Las desobedientes: Mujeres de nuestra América. Bogotá: Panamericana Editorial, 1997.

CABELLO DE CARBONERA, Mercedes. Influencia de la mujer en la civilización. El Álbum, n. 12, Lima, 8 de agosto de 1874

CARRILLO, Francisco. Clorinda Matto de Turnery su indigenismo literario. Lima: Biblioteca Nacional, 1967.

CIXOUS, Hélène. La risa de Medusa: Ensayos sobre la escritura. Barcelona: Anthropos, 1995.

CORNEJO POLAR, Antonio. Escribir en el aire. Ensayo sobre la heterogeneidad socio cultural en las literaturas andinas. Lima: Horizonte, 1994.

CORNEJO POLAR, Antonio. Clorinda Matto de Turner, novelista. Lima: Lluvia Editores, 1992.

CORNEJO POLAR, Antonio. El sentido de la narrativa de Arguedas. Revista Peruana de Cultura, Lima, n. 13-14, 1971.

DUNBAR TEMPLE, Ella. Curso de la literatura femenina a través del período colonial en el Perú. Revista 3. Lima, p. 25-56, 1939 
ENTREVISTA A LAURA RIESCO. El Comercio. Lima, mayo de 1995

FORGUES, Roland. Palabra viva. Narradores. Lima: Libreria Studium Ediciones, 1988. Tomo I.

GONZÁLEZ VIGIL, Ricardo. La gran novela de Laura Riesco. El Comercio, Lima, 22 de enero de 1995.

GUARDIA, Sara Beatriz. Mujeres Peruanas. El otro lado de la historia. 5ta. ed. Lima: 2013.

GUTIÉRREZ, Miguel. Los andes en la novela peruana actual. Lima: Editorial San Marcos, 1999.

LÓPEZ LENCI, Jazmín. Patria de ensueño digno pais de Utopía. In: SIMPOSIO INTERNACIONAL AMAUTA Y SU ÉPOCA. Lima: Librería Editorial Minerva, 1998.

MARIÁTEGUI, José Carlos. 7 Ensayos de interpretación de la realidad nacional. Lima: Empresa Editora Amauta, 1992, Quincuagésima Séptima Edición. https://doi.org/10.2307/978561

MARTOS, Marco. Apuntes sobre Ximena de dos caminos de Laura Riesco. In: FORGUES, Roland (comp.) Mujer, creación y problemas de identidad femenina en América Latina. Mérida: Universidad de los Andes. 1999. https://doi.org/10.30920/letras.88.128.12

MATTALIA, Sonia. Máscaras suele vestir. Pasión y revuelta: escrituras de mujeres en América Latina. Madrid: Iberoamericana - Vervuert, 2003. https://doi. org/10.31819/9783865278067

MATTO DE TURNER, Clorinda. Aves sin nido. Miami: Stockcero, 2004.

MATTO DE TURNER, Clorinda. Aves sin nido. [S. l.]: [s. n.], 1889.

MATTO DE TURNER, Clorinda. Las obreras del pensamiento en la América del Sud. Búcaro Americano, [S. l.], Año I, n. 1, 1 feb. 1896 . https://doi.org/10.6035/ asparkia.2016.29.12

RIESCO, Laura. Ximena de dos caminos. Lima: Peisa, 1994.

RIVERA MARTÍNEZ, Edgardo. El mundo de la ternura, crueldad y poesia. El Mundo, Lima, 7 de enero de 1995

TAMAYO VARGAS, Augusto. Literatura Peruana. Lima: José Gomadard, Editorm 1968. Tomo II.

TAURO, Alberto. Clorinda Matto de Turner y la Novela Indigenista. Lima: Universidad Nacional Mayor de San Marcos, 1976. https://doi.org/10.2307/4529842

VELARDE, Elsa. Clorinda Matto de Turner y su obra. Tesis para optar el Grado de Bachiller en Humanidades. Universidad Nacional de San Agustín, Facultad de Letras, Arequipa, 1943. https://doi.org/10.22201/ facmed.20075057e.2018.27.1895

\section{Endereço para correspondência}

Sara Beatriz Guardia

Av. Honorio Delgado 430, San Martín de Porres 15102.

\section{Sara Beatriz Guardia}

Sara Beatriz Guardia, escritora peruana. Directora de la Cátedra UNESCO Patrimonio Cultural y Turismo Sostenible de Universidad de San Martín de Porres. Lima-Perú. Directora del Centro de Estudios La Mujer en la Historia de América Latina, CEMHAL. Directora de la Cátedra José Carlos Mariátegui. Es autora de doce libros, y de nueve en la dirección de edición. 